\title{
Lesões histopatológicas renais causadas por Dirofilaria immitis (Leidy, 1856) em cães infectados experimentalmente
}

\section{Renal histopathology lesion by Dirofilaria immitis (Leidy, 1856) in dogs experimentally infected}

\author{
Elan Cardozo Paes de Almeida, ${ }^{\star}$ Ana Maria Reis Ferreira, ${ }^{\star \star}$ Norma Vollmer Labarthe, ${ }^{\star \star \star}$ \\ Maria Lucia Ribeiro Caldas, ${ }^{\star \star \star \star}$ John W. McCall ${ }^{\star \star \star \star \star}$
}

\begin{abstract}
Resumo
Foram estudadas lesões renais de 17 cães da raça Beagle, infectados experimentalmente com o parasita Dirofilaria immitis através de transplante de parasita adulto ou por injeção subcutânea de larva infectante, com o período de infecção variando de 111 a 923 dias. Os animais foram separados em seis grupos de acordo com o tempo de duração e tipo de infecção e um grupo controle composto por 11 cães da mesma raça. As amostras renais foram obtidas por necropsia e examinadas através da microscopia óptica pelas colorações de hematoxilina-eosina, ácido periódico de Schiff, prata-metanamina e tricrômico de Masson. Nos grupos de cães infectados a alteração glomerular mais freqüente foi o aumento da celularidade mesangial, associado ou não à presença de microfilárias intracapilares ou intersticiais. Nos grupos com tempo de infecção acima de 365 dias foram observadas alterações glomerulares como espessamento de membrana basal glomerular e nefrite intersticial Esses achados preliminares confirmam relatos anteriores sugerindo que a glomerulonefrite e a nefrite intersticial são as principais lesões renais associadas a cães infectados por $D$. immitis.
\end{abstract}

Palavras-chave: Dirofilaria immitis, dirofilariose, glomerulonefrite, nefrite intersticial, rim, cão.

\begin{abstract}
Necropsy kidney from beagles infected with Dirofilaria immitis were studied by optical microscopy. Experimental infections were done either through adult worms transplantation or by subcutaneous infection of infective larvae. Infection duration varied from 111 to 923 days: Seventeen beagles, five to twenty one months old were divided in six experimental groups and one control group (11 dogs), according to infection duration and kind. Kidney samples were taken during necropsy and were stained by hematoxilin-eosin (H\&E), periodic acid Shiff's (PAS), silver-meatanamine and Masson's trichrome staining. The most frequent glomerular lesion found was increased mesangial celullarity associated or not with intracapilary or interstitial microfilaria presence. When infection duration was longer than 365 days glomerular basal membrane thickening and interstitial nephritis were observed. These preliminary findings confirm previous reports suggesting that glomerulonephritis and interstitial nephritis are the main renal lesions developed by $D$. immitis infected dogs.
\end{abstract}

Keywords: Heartworm, Dirofilaria immitis, dirofilariasis, glomerulonephritis, interstitial nephritis, kidney; dog.

\section{Introdução}

Dirofilaria immitis ( $D$. immitis) é um filarídeo da família Onchocercidae, parasita de ventrículo direito e artérias pulmonares de mamíferos, principalmente cães domésticos. ${ }^{12}$ As lesōes mais significativas da doença são encontradas nas artérias pulmonares. ${ }^{6.13 .18}$ Além das lesões no sistema cardiovascular, outros órgãos podem ser afetados, entre eles os rins. ${ }^{18.21}$ O comprometimento renal se faz por um ou mais mecanismos como: distúrbios pré-renais, respostas imunomediadas do hospedeiro ou efeito direto dos parasitas. ${ }^{\text {i7 }}$ Embora lesões renais ocorram com freqüência nos cães parasitados, o aparecimento de falência renal e uremia são menos comuns ${ }^{17}$ e estes cães desenvolvem proteinúria ${ }^{3.4,8.14 .17}$ devida a uma alteração funcional na membrana basal glomerular. ${ }^{4}$ \footnotetext{
*Professora do Departamento de Patologia (M.V. MSc) - Universidade Federal Fluminense (UFF) - Rua Marquês do Paraná, 303 - HUAP - 40 andar
- Centro - NT - RJ, CEP 24030-210.

**Professora do Departamento de Patologia (M.V. MSc Doutor) - Universidade Federal Fluminense (UFF) - Rua Marquês do Paraná, 303 - HUAP - $4^{\circ}$ andar - Centro - NT - RJ, CEP 24030-210.

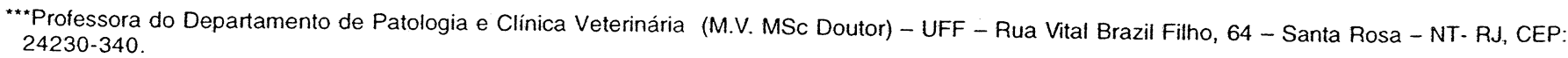

***Professora do Departamento de Patologia (M. MSc Doutor) - Universidade Federal Fluminense (UFF) - Rua Marquês do Paraná, 303 - HUAP $4^{\circ}$ andar - Centro - NT - RJ, CEP 24030-210.

****Department of Medical Microbilogy and Parasitology (MSc. PhD) - University of Georgia - Athens, GA - USA.
} 
As lesões renais nos cães parasitados são variadas e descritas como: glomerulopatia por complexo imune, glomeruloesclerose, nefrite intersticial crônica e amiloidose. ${ }^{18}$ As lesões histopatológicas observadas nos glomérulos variam de leve a grave ${ }^{8,20}$ e são descritas como: espessamento da membrana basal glomerular, ${ }^{2,5,8,11.16,18,20}$ presença de crescente fibrocelular ao longo da cápsula de Bowman, ${ }^{16}$ aumento no número de células mesangiais e matriz mesangial, ${ }^{1,2.8 .16}$ lesões escleróticas glomerulares focais, ${ }^{1}$ microfilárias nos capilares glomerulares e peritubulares ${ }^{1,2,5,8,14,15}$ e lesões 10cais ou difusas de nefrite intersticial. ${ }^{14.18,19}$

O presente estudo foi realizado para identificar e descrever as lesões renais, através de microscopia óptica, provocadas em cães infectados experimentalmente por $D$. immitis com diferentes cargas parasitárias em diferentes períodos de tempo.

\section{Material e métodos}

\section{Cães}

Dezessete cães da raça Beagle, com idades variando entre 5 a 21 meses (9 machos, 4 fêmeas e 4 machos castrados) foram infectados experimentalmente com o parasita Dirofilaria immitis.
A infecção experimental foi realizada pelo Dr. J. McCall no T.R.S. Laboratories, Athens, GA - EUA, onde 13 animais foram infectados por injeção subcutânea na região inguinal com 50 ou 400 larvas de terceiro estágio $\left(\mathrm{L}_{3}\right)$, como descrito anteriormente, ${ }^{21}$ e quatro animais receberam transplante via veia jugular direita de 18 vermes de 5 meses ou 35 vermes adultos. ${ }^{7}$

Onze cães da mesma raça, 10 fêmeas e 1 macho, com idades entre 18 e 36 meses, não foram infectados, sendo utilizados como controle.

Os animais foram mantidos em canis telados, com piso isolando-os dos dejetos e receberam ração balanceada comercial duas vezes ao dia e água ad libidum. Posteriormente foram submetidos a eutanásia, respeitando-se o bem-estar animal, entre 111 e 923 dias após a infecção.

No dia da eutanásia uma amostra de sangue venoso em EDTA foi retirada para contagem de microfilárias: $A$ amostra sangüínea foi submetida ao teste de Knott modificado (Newton \& Wright, 1956) para contagem de microfilárias.

Os cães foram separados em seis grupos (de A a F) de acordo com o tipo ( $50 \mathrm{~L} 3,400 \mathrm{L3}, 18$ vermes ou 35 vermes) e o tempo de infecção $(111,325,365,419,818$ ou 923 dias) e um grupo controle (grupo G), como demostrado na Tabela 1.

Tabela 1: Animais separados em grupos de acordo com o tipo e tempo de infecção.

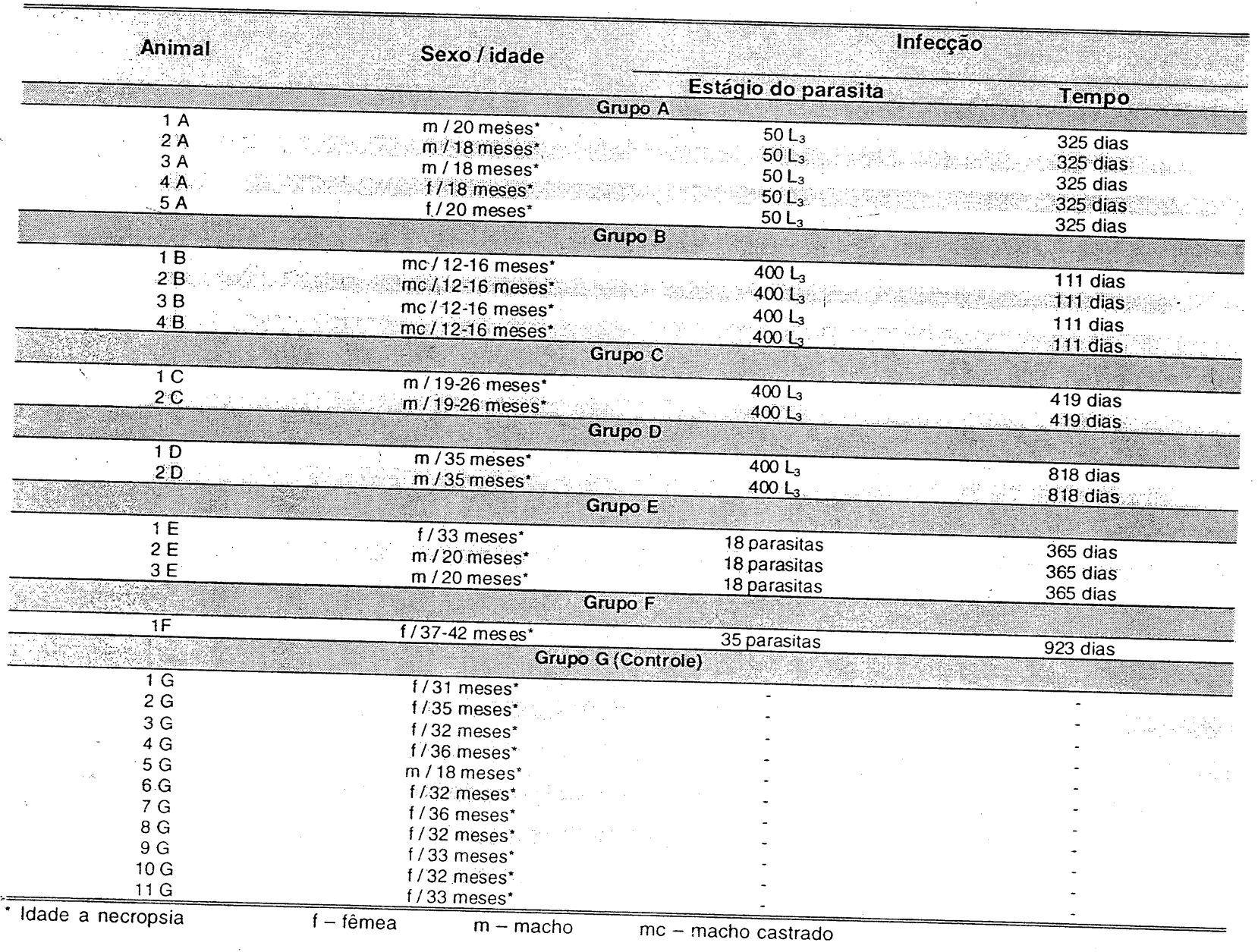




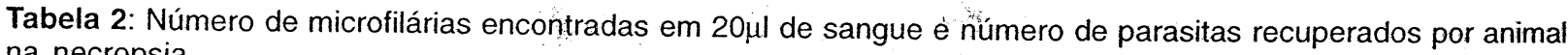
na necropsia.

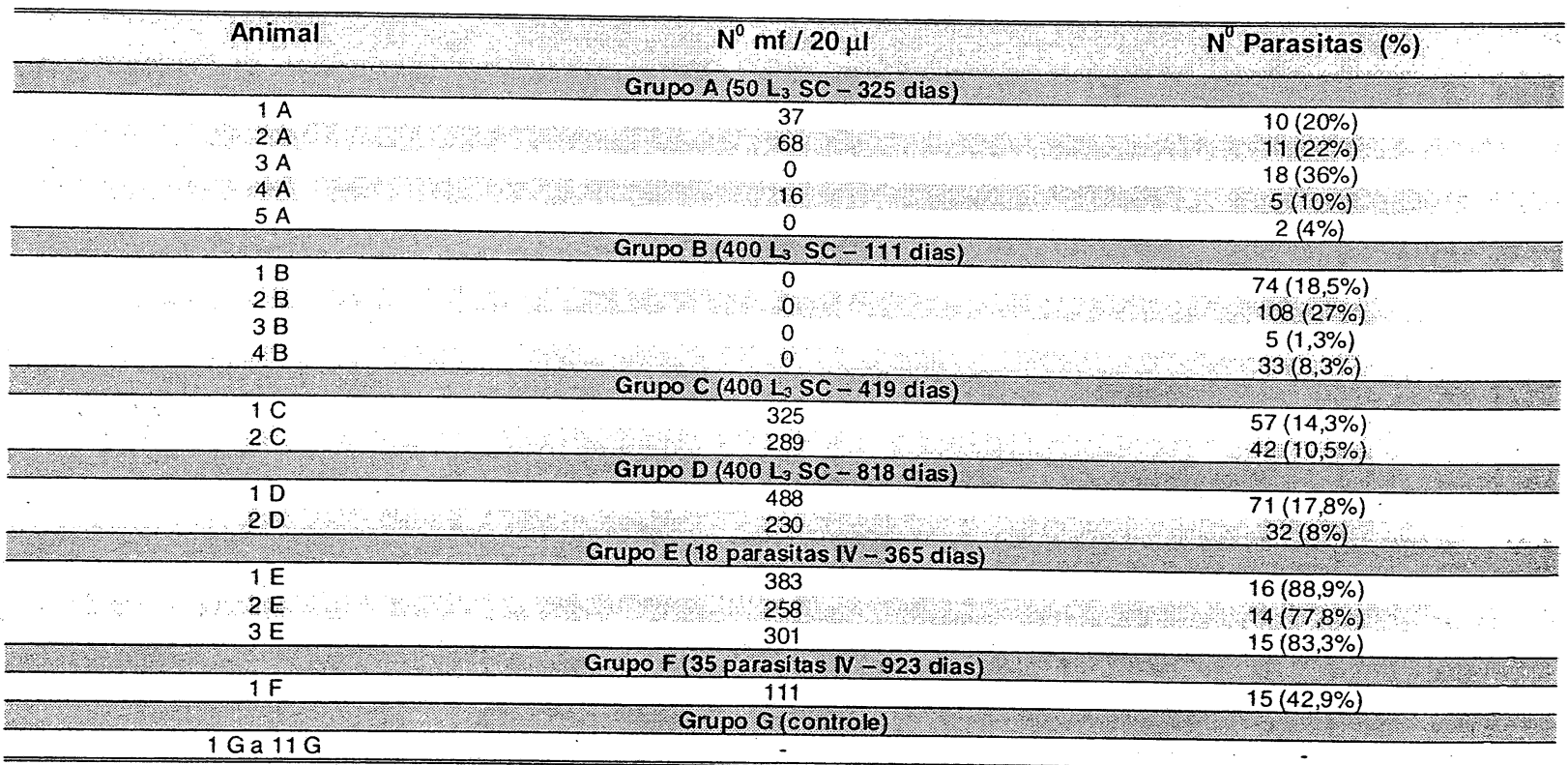

Tabela 3: Alterações histopatológicas encontradas nos rins de cães infectados experimentalmente por $D$. immitis.






\section{Necropsia e análise das alterações macroscópicas}

Todos os animais foram necropsiados. As cavidades torácica e abdominal foram abertas e inspecionadas à procura de vermes livres e todos os órgãos foram analisados macroscopicamente. O bloco do coração com os pulmões foi examinado primeiramente abrindo-se o coração direito e circundando todo o átrio e ventrículo direitos. A artéria pulmonar foi aberta seguindo suas ramificações em todos os lobos pulmonares. Todos os parasitas encontrados no interior do coração direito e na artéria pulmonar e suas ramificações, como também os vermes livres foram contados. Os rins foram remetidos pelo TRS Laboratories, embebidos em formol $10 \%$ tamponado para o processamento e análise no Laboratório de Histopatologia do Departamento de Patologia - Hospital Universitário Antônio Pedro / Universidade Federal Fluminense. Após análise macroscópica foram colhidas amostras de tecido renal, contendo córtex e medula, fixadas em formol tamponado a $10 \%$, para processamento e estudo em microscopia óptica.

\section{Microscopia óptica}

As amostras foram clivadas em fragmentos de 2 a $4 \mathrm{~mm}$ de espessura, identificadas e incluídas em parafina. As colorações utilizadas foram: hematoxilina-eosina (H\&E), ácido periódico de Schiff (PAS), prata-metanamina de Jones e tricrômico de Masson. As alterações identificadas à microscopia óptica como espessamento de membrana basal glomerular, esclerose glomerular segmentar ou global e microfilárias nos capilares e/ ou interstício foram determinadas como ausente (A) ou presente $(P)$ e as alterações identificadas como proliferação celular mesangial, aumento de matriz mesangial e nefrite intersticial foram semiquantificadas numa escala de 0 a $3+(0=$ nenhuma, $1+=$ discreta, $2+=$ moderada e $3+=$ acentuada) (Tabela 3 ).

\section{Resultados}

O número de microfilárias por $20 \mu \mathrm{l}$ de sangue e o número de parasitas recuperados na necropsia, por animal, são apresentados na Tabela 2.

Macroscopicamente foram observadas alterações na coloração do tecido renal fixado em 12 dos 17 cães infectados experimentalmente por Dirofilaria immitis. Estas alterações estavam representadas por manchas acinzentadas no córtex, estrias esbranquiçadas entre cortical e medular, medula de coloração castanha escura, estrias acastanhadas na medula. No cão $1 \mathrm{~F}$ foram encontradas áreas deprimidas na superfície da córtex renal.

As principais lesões renais observadas à microscopia óptica estão demonstradas na Tabela 3. Em todos os grupos a alteração glomerular mais constante foi o aumento da celularidade mesangial (Figura 1), associada ou não à presença de microfilárias intracapilares ou intersticiais (Figura 2).

No grupo A foi encontrada discreta proliferação mesangial, alteração esta que também foi encontrada nos demais animais dos outros grupos, variando de ausente (1C) a moderada $(2 \mathrm{~B}, 4 \mathrm{~B}, 1 \mathrm{D}, 2 \mathrm{D}, 2 \mathrm{E}, 3 \mathrm{E}, 1 \mathrm{~F})$. Todos os cães dos grupos infectados possuiam microfilaremia, exceto os cães do grupo B (com 111. dias de infecção) e dois dos cinco cães do grupo A (animais 3 e 5). Além disto os cães do grupo A apresentaram microfilaremia baixa e três dos cinco cães (ani-

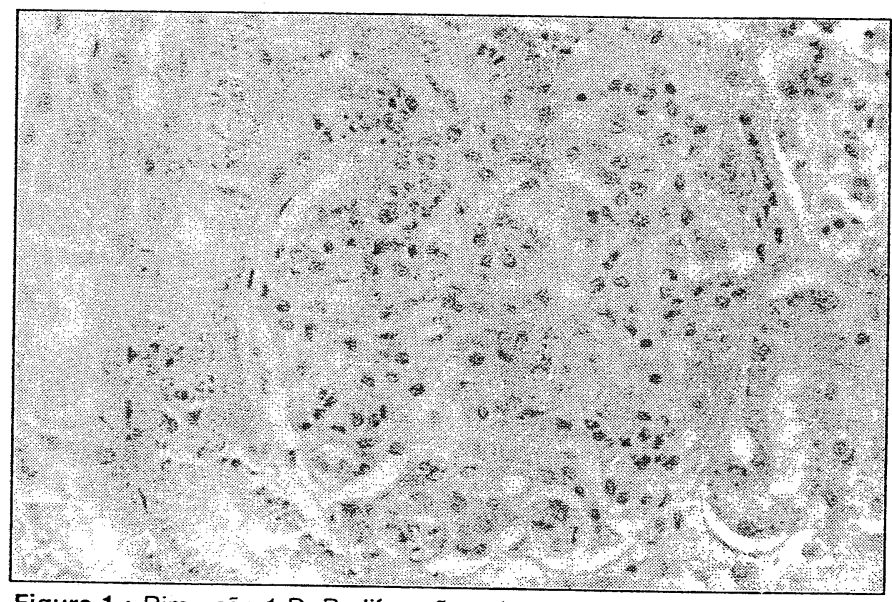

Figura 1 : Rim - cão $1 \mathrm{D}$ : Proliferação celular mesangial (HE - $40 \mathrm{X}$ neg.).

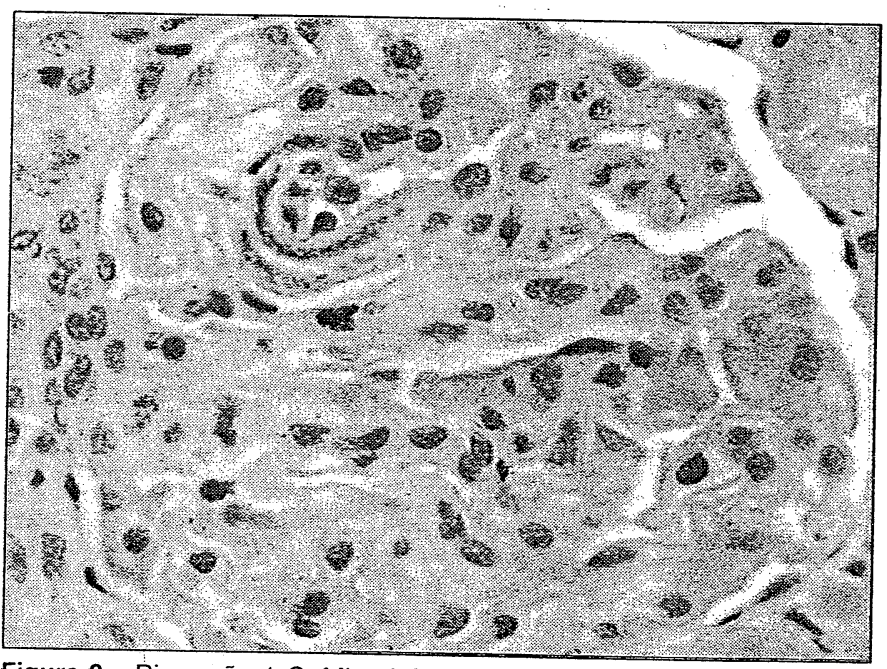
Figura 2 : Rim - cão $1 \mathrm{C}$ : Microfilária no capilar glomerular (seta) (HE
$40 \times$ neg.).

mais 1,3 e 5) não demonstraram microfilárias nos capilares e/ou interstício. Nos grupos C, D, E e F foram vistas alterações glomerulares mais graves, como espessamento de membrana basal glomerular (MBG) (Figura 3). Apenas no gru-



Figura 3 : Rim - cão $1 \mathrm{D}$ : Espessamento de membrana basal glomerular (PMJ - $40 \times$ neg.). 
po $\mathrm{E}$ e no cão $4 \mathrm{~A}$ foram encontrados aumento da matriz mesangial (Figura 4). Outras lesões evidenciadas foram: esclerose glomerular focal segmentar e/ou global (Figura 5) em grupos diferentes e em apenas um animal de cada grupo ( $3 A, 1 D$ e $1 E)$. $O$ achado de crescente fibrocelular foi raro, sendo evidenciado somente em um cão (1E).

Alguns animais mostraram nefrite intersticial caracterizada por infiltrado inflamatório mononuclear e focos de atrofia tubular, fibrose intersticial e pielite (Figura 6). Nos animais do grupo controle não foram evidenciadas alterações histopatológicas renais significativas.

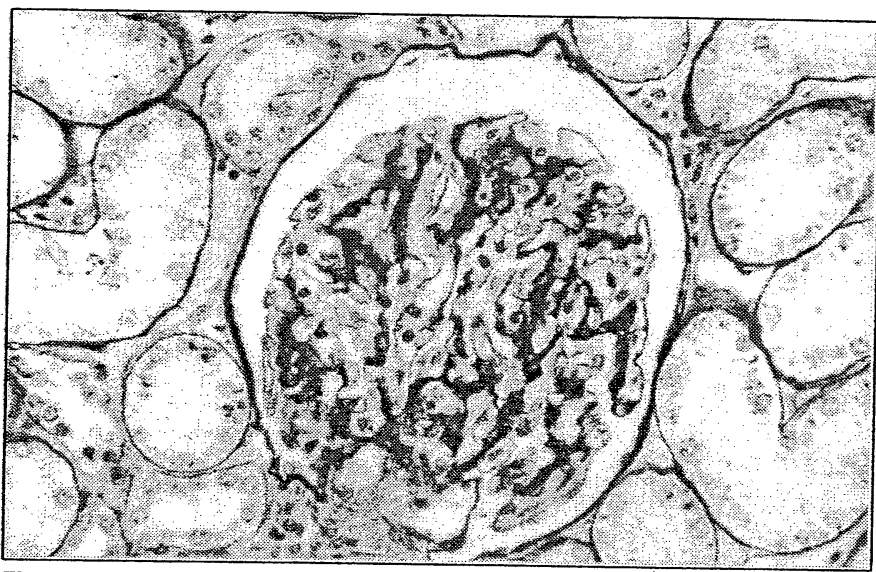

Figura 4: Rim - cão $1 \mathrm{E}$ : Aumento de matriz mesangial (PMJ - $40 \mathrm{X}$ neg.).

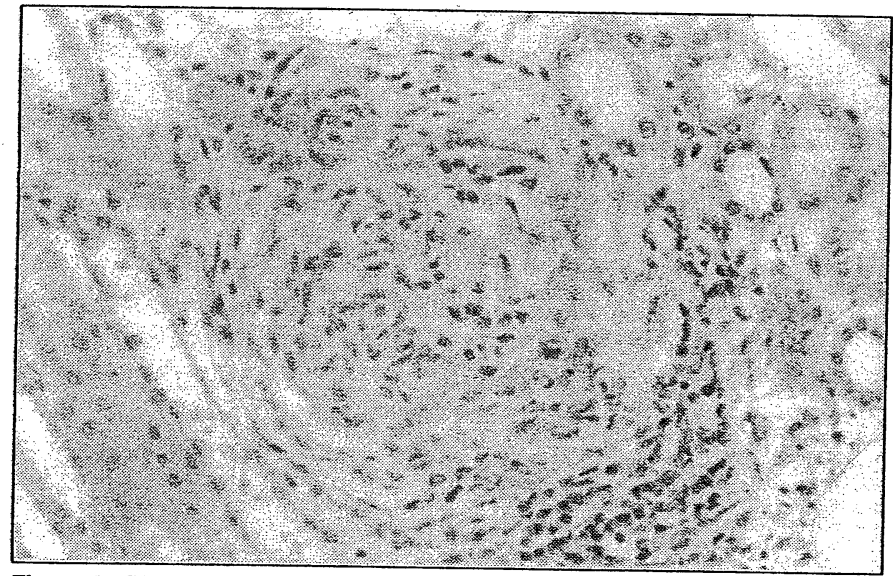

Figura 5: Rim - cão $1 \mathrm{E}$ : Esclerose glomerular focal e global (HE - $40 \mathrm{X}$ neg.)

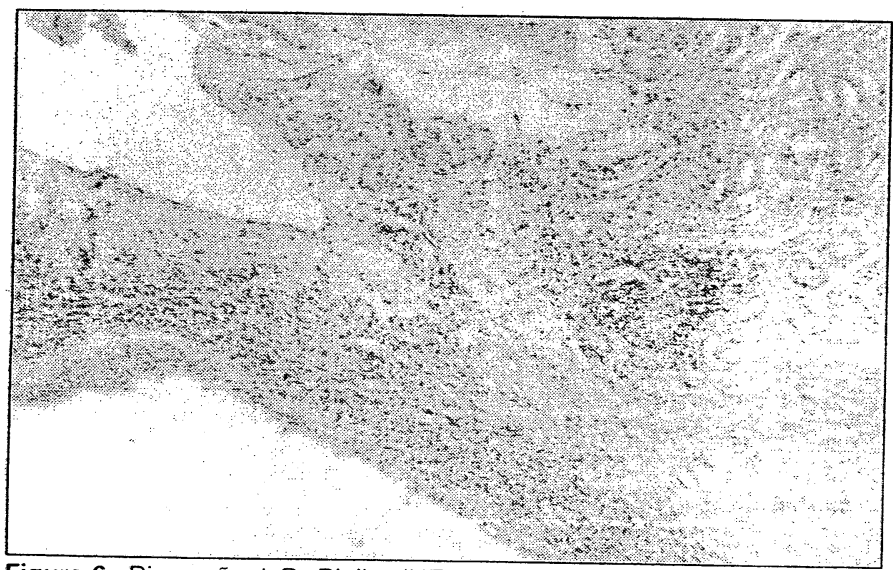

Figura 6: Rim - cão $1 \mathrm{D}$ : Pielite (HE - $10 \times$ neg.)

\section{Discussão e conclusão}

Apesar de terem sido encontradas alterações macroscópicas na coloração dos rins dos cães infectados, não houve associação entre este aspecto, carga parasitária e alterações microscópicas. Alguns rins apresentavam-se macroscopicamente normais, mas mostravam lesões histopatológicas importantes.

Os resultados deste trabalho reafirmam que as principais lesões renais associadas a cães infectados por $D$. immitis são glomerulonefrite e nefrite intersticial, confirmando dados da literatura. ${ }^{114,15,19,20}$ Algumas das alteraçōes evidenciadas caracterizavam histopatologicamente a glomerulonefrite membranoproliferativa. ${ }^{8,14,15,20}$

As alterações histopatológicas observadas nos glomérulos dos cães variavam de leve a moderada; sendo semelhantes aos relatos da literatura. , $2,5,8-11,14-16,19,20$ As lesões renais mais representativas foram evidenciadas nos animais com mais de um ano de infecção e com microfilaremia mais alta. Porém, no grupo $B$, os animais com 111 dias de infecção não possuíam microfilárias na circulação, nem nos capilares e/ou interstício renal e apresentavam alterações glomerulares caracterizadas por proliferação mesangial celular discreta a moderada. Este achado sugere que microfilárias possuem papel limitado na formação da glomerulonefrite, coincidindo com relatos anteriores de patologia renal em infecções ocultas. ${ }^{23} \dot{E}$ provável, portanto, que a glomerulonefrite em cães infectados pela $D$. immitis esteja associada à quantidade de parasitas adultos, como já foi relatado anteriormente. ${ }^{15,16}$ Estes pesquisadores demostraram que complexos imunes na circulação correlacionaram-se significativamente com o número de parasitas adultos, mas não com a microfilaremia. ${ }^{15}$ Posteriormente, estes autores produziram anticorpos monoclonais específicos para o parasita adulto da $D$. immitis, reativos com microfilárias. Foi encontrada correlação significativa entre o nivel de antígenos na circulação e a carga de parasitas adultos, sugerindo que os antígenos liberados pelos parasitas adultos fazem parte do complexo imune na circulação de cães infectados. ${ }^{16}$ Todos os cães infectados, até mesmo os do grupo $B$, que não apresentavam microfilárias na circulação, exibiam lesões renais. Destes animais foram recuperados parasitas das artérias pulmonares, seus ramos e do ventrículo direito, o que mostra a importância de parasitas adultos na patogênese renal, confirmando trabaIhos anteriores. ${ }^{15,16}$

Considera-se de grande importância para a compreensão da fisiopatologia renal da dirofilariose, a melhor caracterização das lesões glomerulares, como as alterações de MBG provocadas por complexos imunes, que seriam responsáveis pela proteinúria. Desta maneira, o tratamento adequado dos animais poderia ser melhor conduzido, corrigindo a função renal e, conseqüentemente, favorecendo o prognóstico. É por este motivo que a avaliação da proteinúria tem sido valorizada como indicador de prognóstico nos protocolos de exames prévios dos pacientes candidatos ao tratamento adulticida. 


\section{Referências}

1 ABRAMOWSKY, C.R. et al. Dirofilaria immitis. 5-Immunopathology of Filarial Nephropathy in dogs. The American Journal of Pathology, v.104, n.1, p.1-12, 1981.

2 AIKAWA, M. et al. Dirofilariasis. IV- Glomerulonephropathy Induced by Dirofilaria immitis infection. Am. J. Trop. Med. Hyg., v.30, n.1, p.84-91, 1981

3 BARSANTI, J.A. Serum and Urine Proteins in Dogs Infected with Dirofilaria immitis. In: Proc. Am. Heartworm Soc., v.77, p. 53-56, 1977

4 BUORO, I.B.J.; ATWELL, R.B. Urinalysis in Canine Dirofilariasis with Emphasis on Proteinuria. Vet. Rec., v.112, p. 252-253, 1983.

5CASEY,H.W. ; SPLITTER, G.A. Membranous Glomerulonephritis in Dogs Infected With Dirofilaria immitis. Vet. Pathol., v.12, p. 111-117,1975.

6 DILLON, R. Diagnosis and Pretreatment Assessment of Heartworm Disease. Expo. Encore Veterinary Technicians, Symbiotics Corp., p. 1-8, 1988 .

7 DZIMIANSKI, M. Dados não publicados, comunicação pessoal, 1998.

8 GRAUER, G.F.; CULHAM, C.A.; COOLEY, A.J. et al. Clinicopathologic and Histologic Evaluation of Dirofilaria immitis-induced Nephropathy in Dog. Am. J. Trop. Med. Hyg., v. 37, p. 588-596, 1987.

9 GRAUER, G.F.; CULHAM, C.A.; BOWMAN, D.D. et al. Parasite Excretory-Secretory Antigen and Antibody to Excretory-Secretoty Antigen in Body Fluids and Kidney Tissue of Dirofilaria immitis Infected Dogs. Am. J. Trop. Med. Hyg., v. 39, n. 4, p. 380-387, 1988.

10 GRAUER, G.F.; CULHAM, C.A.; DUBIELZIG, R.R. et al. Experimental Dirofilaria immitis-Associated Glomerulonephritis Induced in Part by in Situ Formation of Immune Complexes in the Glomerular Capillaty Wall. J. Parasitol., v. 75, n. 4, p. 585-593, 1989.

11 KLEI,T.R.; CROWELL, W.A.; THOMPSON,P.E. Ultrastructural Glomerular Changes Associated With Filariasis. Am. J. Trop. Med. Hyg., v. 23, n. 4, p. 608-618, 1974.

12 LOK, J.B. Dirofilaria sp. Taxonomy and Distribution. In: BOREHAM, P.F. \& ATWEL, R.B. (ed.) Dirofilariasis. Florida: CRC Press, 1988 p.1-18.
13 LOMBARD, C.W. Heartworm Disease . In: BONAGURA, J.D. (Ed.) Cardiology, New York: Churchill Livingstone, 1987, p. 275-299.

14 LUDDERS, J.W. et. al. Renal Microcirculatory and Correlated Histologic Changes Associated with Dirofilariasis in Dogs. Am. J. Vet. Res., v. 49, n. 6, p. 826-830, 1988.

15 NAKAGAKI, K., HAYASAKI, M.; OHISHI.I. Histopathological and Immunopathological Evaluation of Filarial Glomerulonephritis in Dirofilaria immitis Infected Dogs. Japan J. Exp. Med., v. 60, n. 4, p. 179-186, 1990.

16 NAKAGAKI, K.; NOGAMI,S.; HAYASAKI, Y. et al. Dirofilaria immitis: Detection of Parasite-Specific Antigen by Monoclonal Antibodies in Glomerulonephritis in Infected Dogs. Parasitol. Res., v. 79, p. 49-54,
1993.

17 OSBORNE, C. A.; HAMMER, R.F., O'LEARY, T.P. Renal Manifestations of Canine Dirofilariasis. In: PROCEEDINGS OF THE HEARTWORMS SYMPOSIUM'80. Veterinary Medicine Publ., Edwardsville, Kan., p.
$67-92,1981$.

18RAWLINGS, C.A. .Others Heartworm Syndromes. In: RAWLINGS, C.A. (Ed.) Heartworm Disease in Dogs and cats. Philadelphia: W.B. Sauders, 1986, p. 175-207.

19 SHIROTA, K.; TAKAHASHI, R.; FUJIWARA, K. et al. Canine Interstitial Nephritis with Special Reference to Glomerular Lesion and Filariasis. Jap. J. Vet. Sci., v. 41, p. 119-129, 1979.

20 SIMPSON, C.F.; GEBHARDT, B.M; BRADLEY, R.E. et al Glomerulosclerosis in Canine Heartworm Infection, Veterinary Pathology, v.11, p. 506-514, 1974

21 SIMPSON, C.F., JACKSON, R.F. Lesions in the Liver and Kidney of Dirofilaria immitis-infected dogs following treatment with ivermectin, Z. Parasitenkunde, v. 71, p. 97-105, 1985.

22 T.R.S. LABS., INC. Experimental Infection of Dogs and Cats with Dirofilaria immitis. Standard Operating Procedures, n. 8.5, p.1-3, 1993.

23WOLFSHEIMER, K.J., WERNER, L. L. Nephrotic Syndrome in a Dog with Occult Heartworm Disease. The Compedium on Continuing
Education, v. 5, n. 5, p. 358-365, 1983. 